\title{
Algo se muere de las Setas a la Alameda. Efectos del turismo sobre la población y el patrimonio en el casco norte de Sevilla
}

La turistificación se define como la apropiación física y simbólica de un territorio por una fuerte intensificación de la actividad turística que impacta en diferentes ámbitos de la vida cotidiana de los residentes, incluidas las expresiones culturales y el patrimonio histórico. La expulsión del vecindario por el auge de los apartamentos turísticos y las operaciones de marketing urbano en el casco norte de Sevilla ha provocado la aparición de movimientos que denuncian los perjuicios que la turistificación provoca en la ciudad. Es el caso de Cactus: Colectivo-Asamblea Contra la Turistización de Sevilla.

María Barrero Rescalvo | investigadora predoctoral, Universidad de Sevilla

URL de la contribución <www.iaph.es/revistaph/index.php/revistaph/article/view/4432>

"Algo se mueve de las Setas a la Alameda". Así se presenta el sector norte del centro histórico en la página web del Consorcio de Turismo de Sevilla ${ }^{1}$, buscando despertar interés en el visitante por esta zona urbana. Al parecer, es una propuesta novedosa respecto a la usual, que se introduce en el circuito turístico solo si la estancia en Sevilla supera las dos noches y para aquellos turistas que buscan la Sevilla menos convencional. Aparece así la marca Feria-Alameda en guías y postales, y el despliegue de todo un imaginario relacionado con la gastronomía, el flamenco, el arte o lo alternativo.

Se menciona, además, la "vibrante personalidad" que "sentirás de manera especial a lo largo del eje que une Las Setas y la Alameda". El mencionado eje barre un espacio urbano tradicionalmente popular y de población con nivel socio-económico medio-bajo, inmerso desde los años noventa en procesos de gentrificación (DÍAZ PARRA, 2014) que hoy se solapan con desplazamiento de residentes o turistificación, causada por el auge de las plataformas de alquiler vacacional como AirBnB. Desde este prisma puede ser acertado mencionar que algo se mueve en el casco histórico norte de Sevilla: su vecindario.

El número de apartamentos turísticos registrados en el barrio de la Feria-Alameda en otoño de 2018 se situaba en torno a $400^{2}$. Un año antes no llegaba a la mitad. Se trata, como en otras ciudades, de un nuevo negocio inmobiliario concentrado en su mayor parte en pocos propietarios en el que se pasa de vivienda a negocio turístico, provocando la marcha involuntaria de parte de la población y dificultando el acceso a otra parte a causa de la reducción de oferta, por lo que resulta difícil saber datos específicos de desplazamiento.

La ciudad histórica no solo se muere si no alberga un vecindario que la habita en su cotidianeidad, también en el momento en que quedan embalsamadas y a disposición de la industria turística (CÓCOLA-GANT, 2011). En esta mercantilización de la vida urbana afloran conflictos entre dos esferas de la ciudad: la productiva (dominada por el sector turístico) y la reproductiva (la del vecindario y sus relaciones sociales), en la que la primera devora a la segunda respondiendo a una lógica global de acumulación por desposesión propia de la ciudad neoliberal (HARVEY, 2004).

Desde esta perspectiva, puede afirmarse que el espacio público se gestiona como un recurso más para seguir acumulando en las grandes urbes, administradas cada vez en mayor medida para crear condiciones para la circulación y acumulación de capital en lugar de para garantizar el desarrollo de una vida digna a sus habitantes (CABRERIZO, 2016). Ejemplos de ello son la privatización de las plazas y calles con terrazas o veladores, la continuada presencia de grupos organizados que dificultan la movilidad cotidiana o la ausencia de espacios para la convivencia más allá del consumo. Esto se suma a la pérdida de comercio de proximidad o a los 


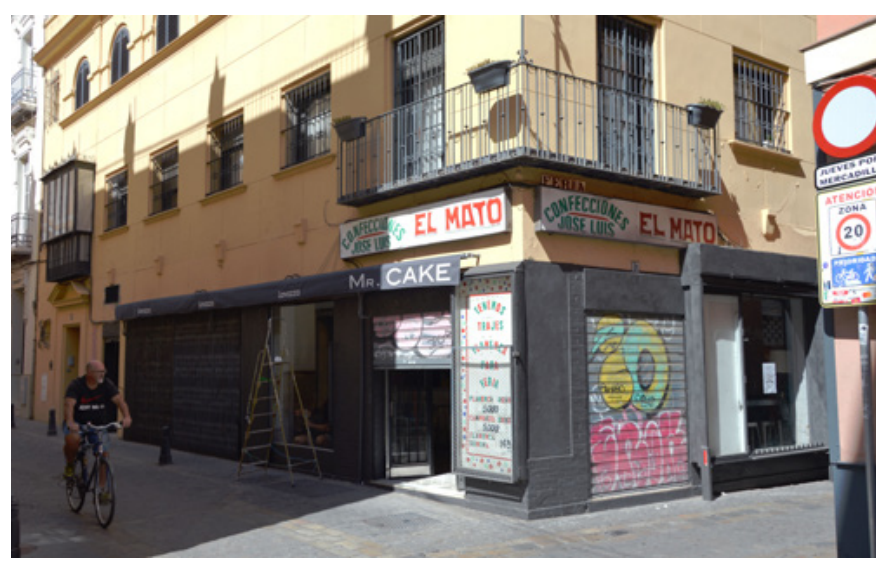

Transformación del tejido comercial en la calle Feria

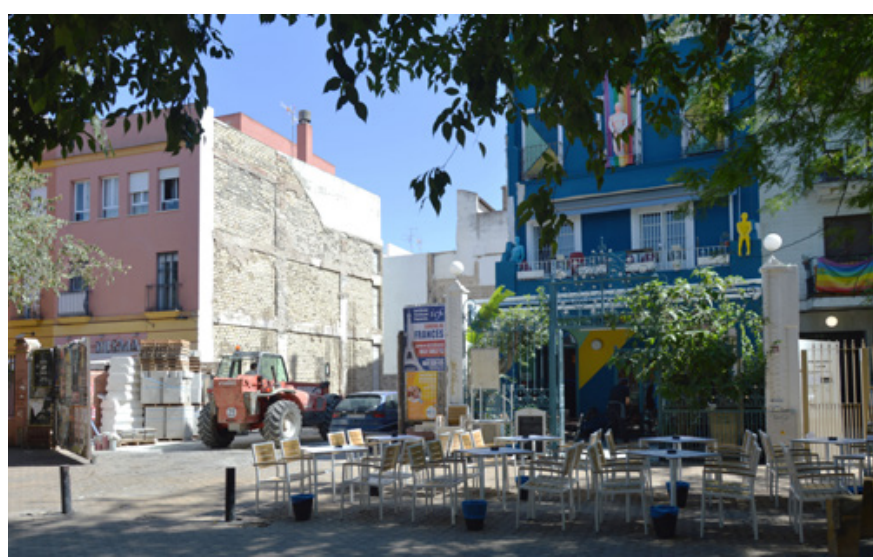

Reconstrucción y veladores en la Alameda de Hércules

elevados índices de contaminación acústica, aspectos que no contribuyen a frenar la despoblación del casco histórico.

El patrimonio no está exento de estas dinámicas en una ciudad cuya agenda turística se fundamenta en el turismo cultural. El destino del paisaje urbano patrimonial sevillano ha quedado supeditado a su aparición o no en los itinerarios turísticos por donde pasaron casi tres millones de visitantes en 2018 (MARTOS, 2019), número que viene batiendo récords cada año. Con estos números, la rápida transformación no solo material, sino también social, cultural y simbólica de los barrios históricos para adaptarse al consumo y al ocio del turista pueden ser altamente perjudiciales para la convivencia vecinal o las economías locales, y también para las identidades sociales o la memoria colectiva (BENACH, 2016).

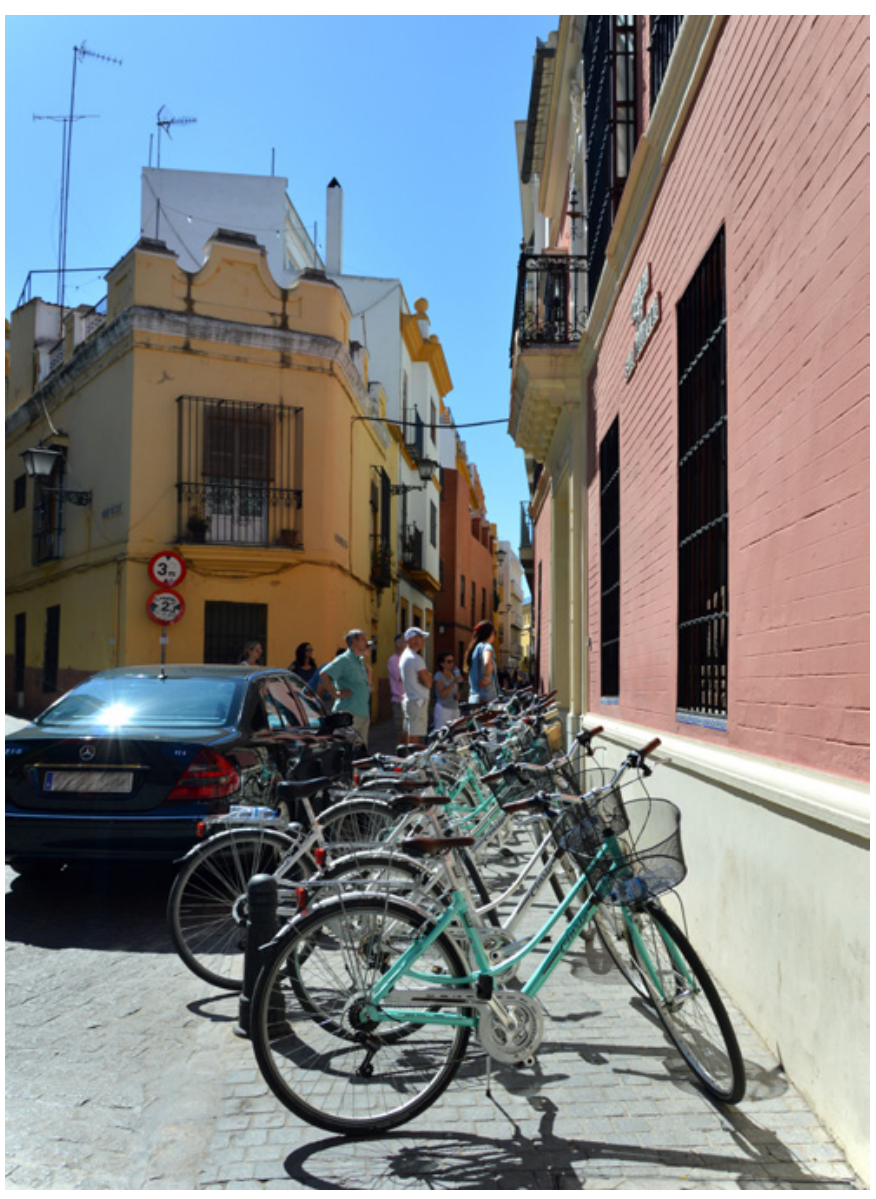

Tour turístico en espacio de tránsito peatonal en plaza de San Martín

Ante este panorama, y junto al impulso de otras ciudades, en Sevilla han surgido voces críticas que desde 2017 han venido promoviendo la organización social como forma de denuncia pública a un modelo turístico aparentemente irrenunciable (JOVER BÁEZ; BERRAQUERO DÍAZ, BARRERO RESCALVO et. ál., 2018), cuestionando los aparentes consensos sociales y políticos sobre los beneficios del turismo y visibilizando los perjuicios de esta actividad económica, también los simbólicos o difícilmente cuantificables, como pueden ser la precariedad laboral (muy feminizada), la huella ecológica, o la pérdida de significados del espacio urbano. Sobre esta última dimensión, la mercantilización del flamenco como hecho cultural popular, o de lugares cargados de complejidad social como el mercado de abastos, ahora gourmet, o la Alameda de Hércules, ahora veladorizada, son referencias recurrentes en la protesta del 


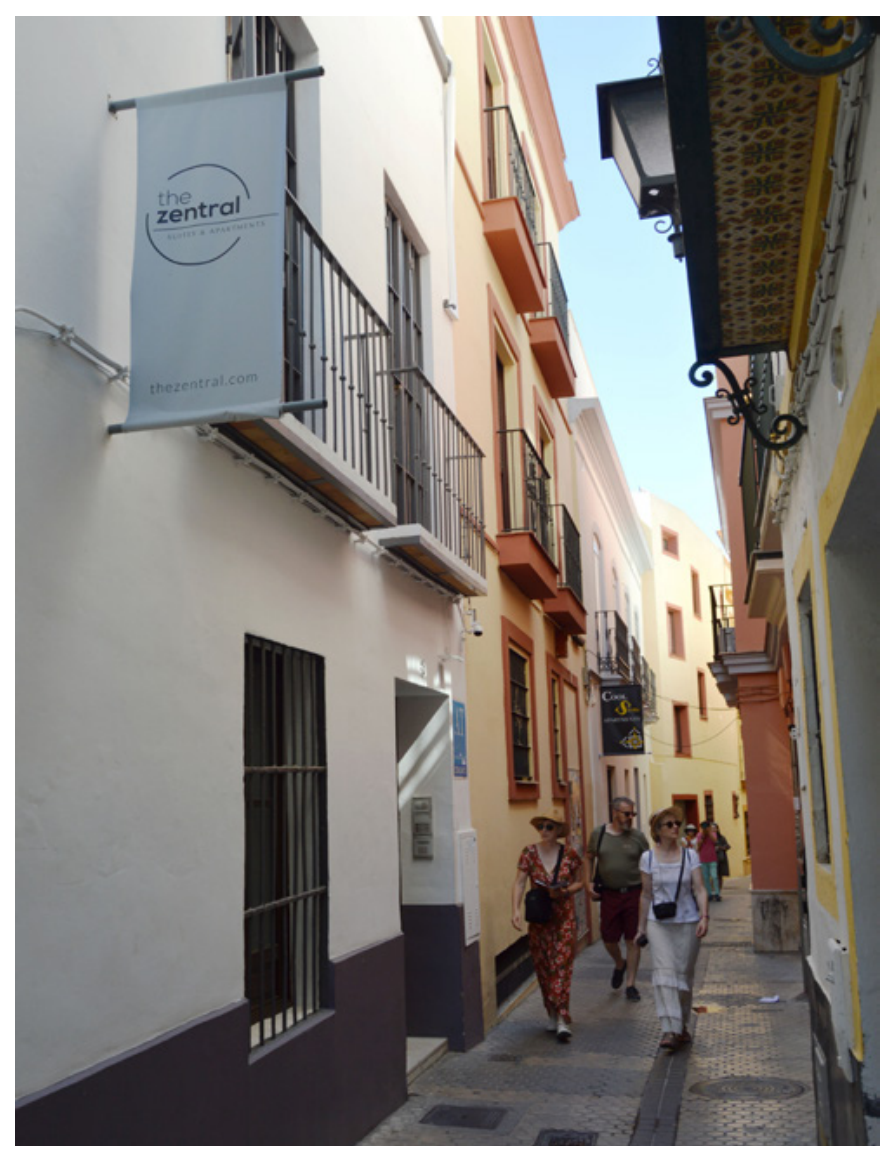

Varios edificios de apartamentos turísticos en calle Morgado | fotos María Barrero Rescalvo, autora de todas las imágenes si no se indica lo contrario

Colectivo Asamblea contra la Turistización de Sevilla (Cactus).

Desde su nacimiento, Cactus $^{3}$ se ha conformado por un grupo heterogéneo de personas y colectivos organizados en su mayoría en el casco norte: asociaciones vecinales, movimientos ecologistas, activistas o académicos. A ello se le suman aquellas alianzas que ha ido tejiendo con movimientos sociales desde un enfoque más amplio, trasladando una crítica integral al modelo de ciudad, y no tanto a la problemática específica del turismo en el centro histórico. Esto cristalizó en la organización del ESTAR (Encuentro Social contra la Turistización: Alternativas y Resistencias) como respuesta a la cumbre internacional de la World Travel and Tourism Council, organizada por el lobby turístico en abril de 2019 en Sevilla a la que acudieron los empresarios

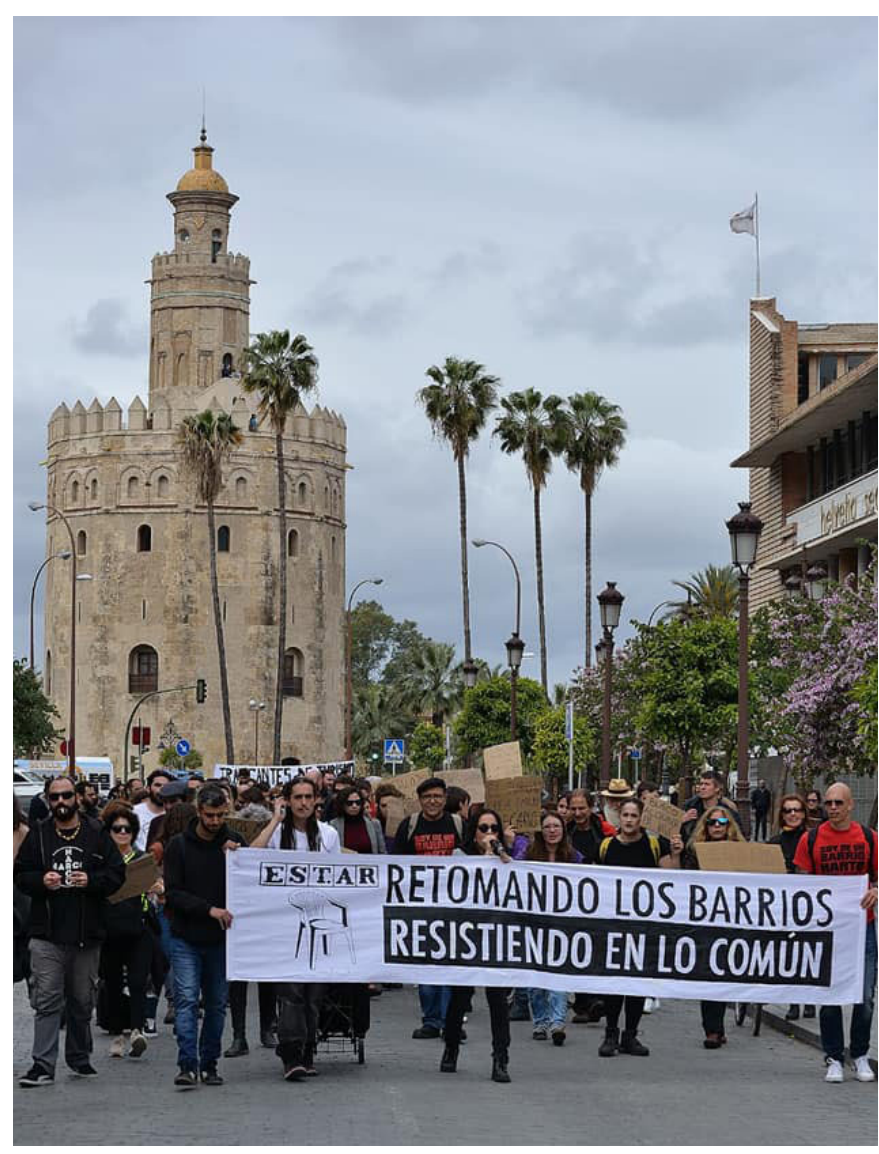

Manifestación en Paseo de Colón (Sevilla) contra la turistificación | foto Lara Santaella

de aerolíneas, cadenas hoteleras y sector bancario más poderosas del mundo, junto a ministros de Turismo de 40 países. Frente a esta cumbre, que fue financiada parcialmente con dinero público municipal -que tanta falta hace en otras lides-, se organizaron mesas redondas, paseos, concentraciones, puntos de información y acciones por las que se interesaron vecinas y vecinos afectados por el impacto del turismo en la ciudad histórica, pero también por el abandono institucional del resto de barrios de Sevilla. AI ESTAR también acudieron colectivos de la Red del Sur de Europa ante la Turistificación (red SET), de la que Cactus forma parte, cooperando con movimientos sociales de Barcelona, Málaga, Palma, Venecia o Lisboa.

En definitiva, en Sevilla han surgido voces que están vislumbrando una realidad que habla de desahucios invi- 
sibles, de pérdida de valores culturales, de deterioro de espacios comunes, de desaparición del tejido vecinal, o de consecuencias ecológicas, que tienen como resultado el vaciamiento del centro histórico y su transformación para satisfacer las demandas de un mercado turístico que crece aparentemente sin límites. Las administraciones local y regional usan, paradójicamente, elementos culturales propios de su devenir histórico y social como valor añadido a un producto capaz de generar atracción para el o la visitante y mayor rédito económico para la industria turística, pero poco o ningún beneficio a las personas que aún permanecen viviendo en estos barrios. De este modo se ha ido favoreciendo una desafección difícilmente reversible por la que el patrimonio cultural, entendido en toda su amplitud, queda condenado a perder su valor de uso.

\section{NOTAS}

1. Véase <https://www.visitasevilla.es/historia/una-rutapor-la-sevilla-mas-polifacetica> [Consulta: 29/05/2019]

2. Según datos del registro de viviendas turísticas de la Junta de Andalucía. El número de apartamentos totales es mucho mayor.

3. <https://cactusevilla.wordpress.com/> [Consulta: 29/09 /2019]

\section{BIBLIOGRAFÍA}

- BENACH, N. (2016) ¿Ciudades en el mapa o en la guía turística? Venta de la ciudad y sentido del lugar. Revista CIDOB d'Afers Internacionals, 113, 2016, pp. 89-105

- CABRERIZO, C. (2016) la ciudad negocio. Turismo y movilización social en pugna. Madrid: Editorial Cisma, 2016

- CÓCOLA-GANT, A. (2011) El Barrio Gótico de Barcelona. De símbolo nacional a parque temático. Scripta Nova. Revista Electrónica de Geografía y Ciencias Sociales [en línea], vol. XV, n. ${ }^{\circ}$ 371, $2011<$ <ttp://www.ub.edu/geocrit/sn/sn-371.htm> [Consulta: 07/06/2019]

- DÍAZ PARRA, I. (2014) ¿Gentrificación o barbarie? Disciplinamiento y transformación social del barrio de la Alameda de Sevilla. Sevilla: Atrapasueños, 2014

- HARVEY, D. (2004) El "nuevo" imperialismo: acumulación por desposesión. Socialist Register [en línea], vol. 40, 2004, pp. 99-129 <https://socialistregister.com/index.php/srv/article/ view/14997> [Consulta: 07/06/2019]

- jover bÁEZ, J.; BERRAQUERO díAZ, L.; BARRERO RESCALVO, M.; JIMÉNEZ TALAVERA, A. (2018) Turistización y movimientos urbanos de resistencia: experiencias desde Sevilla. En MILANO, C.; MANSILLA, J. (ed.) Ciudad de vacaciones. Conflictos urbanos en espacios turísticos. Barcelona: Pol.len, 2018, pp. 403-437

- MARTOS, E. (2019) Sevilla es la tercera ciudad con más turistas de España. ABC Sevilla [en línea], 21 de mayo de $2019<$ https://sevilla.abc.es/sevilla/sevi-sevilla-tercera-ciudadmas-turistas-espana-201905211332_noticia.html> [Consulta: 29/05/2019] 